\title{
Aspirin Protects against Acinar Cells Necrosis in Severe Acute Pancreatitis in Mice
}

\author{
Guotao Lu, ${ }^{1,2}$ Zhihui Tong, ${ }^{1}$ Yanbing Ding, ${ }^{2}$ Jinjiao Liu, ${ }^{3}$ Yiyuan Pan, ${ }^{1}$ Lin Gao, \\ Jianfeng Tu, ${ }^{1,4}$ Yuhui Wang, ${ }^{3}$ George Liu, ${ }^{3}$ and Weiqin $\mathrm{Li}^{1}$ \\ ${ }^{1}$ Surgical Intensive Care Unit (SICU), Department of General Surgery, Jinling Hospital, Medical School of Nanjing University, \\ No. 305 Zhongshan East Road, Nanjing, Jiangsu Province 210002, China \\ ${ }^{2}$ Department of Gastroenterology, Affiliated Hospital of Yangzhou University, Yangzhou, China \\ ${ }^{3}$ Key Laboratory of Molecular Cardiovascular Science Ministry of Education, Institute of Cardiovascular Science, \\ Peking University, Beijing, China \\ ${ }^{4}$ Department of Emergency, Zhejiang Provincial People's Hospital, Zhejiang, China
}

Correspondence should be addressed to Yuhui Wang; wangyuhui2009@bjmu.edu.cn and Weiqin Li; lwqsaplab@163.com

Received 11 July 2016; Revised 7 November 2016; Accepted 23 November 2016

Academic Editor: Andrea Mencarelli

Copyright (C) 2016 Guotao Lu et al. This is an open access article distributed under the Creative Commons Attribution License, which permits unrestricted use, distribution, and reproduction in any medium, provided the original work is properly cited.

\begin{abstract}
Aspirin has a clear anti-inflammatory effect and is used as an anti-inflammatory agent for both acute and long-term inflammation. Previous study has indicated that aspirin alleviated acute pancreatitis induced by caerulein in rat. However, the role of aspirin on severe acute pancreatitis (SAP) and the necrosis of pancreatic acinar cell are not yet clear. The aim of this study was to determine the effects of aspirin treatment on a SAP model induced by caerulein combined with Lipopolysaccharide. We found that aspirin reduced serum amylase and lipase levels, decreased the MPO activity, and alleviated the histopathological manifestations of pancreas and pancreatitis-associated lung injury. Proinflammatory cytokines were decreased and the expression of NF- $\kappa \mathrm{B}$ p65 in acinar cell nuclei was suppressed after aspirin treatment. Furthermore, aspirin induced the apoptosis of acinar cells by TUNEL assay, and the expression of Bax and caspase 3 was increased and the expression of Bcl-2 was decreased. Intriguingly, the downregulation of critical necrosis associated proteins RIP1, RIP3, and p-MLKL was observed; what is more, we additionally found that aspirin reduced the COX level of pancreatic tissue. In conclusion, our data showed that aspirin could protect pancreatic acinar cell against necrosis and reduce the severity of SAP. Clinically, aspirin may potentially be a therapeutic intervention for SAP.
\end{abstract}

\section{Introduction}

Acute pancreatitis (AP) is a complex pathological process, depending on autodigestion caused by premature activation of zymogens. Most cases of AP are mild, with recovery period within 5-7 days by conservative treatment. Nonetheless, there is about $15 \%-20 \%$ of patients under a severe, protracted course leading to lethal attacks [1-3]. Numerous studies showed that pancreatic necrosis is crucial for the development of mild acute pancreatitis (MAP) to severe acute pancreatitis (SAP) [4-6].

MAP has a short course, and the pancreatic structure and function could be fully restored, while, in SAP, once the acinar cells necrosis happened, the rupture of acinar cell membrane could release a series of inflammatory factors, including
TNF- $\alpha$ and IL-6, resulting in systemic inflammatory response syndrome; at the same time, the pancreatic structure and function would be damaged seriously. A large number of clinical and experimental researches suggest that, after AP, especially after SAP, endocrine and exocrine function of the pancreas often suffer varying degrees of damage, even developing permanent sequelae of pancreatic dysfunction [79]. Therefore, protecting acinar cell against necrosis in the early phase of AP would play a vital role in the pathological processes of AP.

Aspirin (Acetylsalicylic Acid, ASA), one of nonsteroidal anti-inflammatory drugs (NSAIDs), is one of the most widely used medications in the world because of a wide range of pharmacological effects, such as anti-inflammatory, analgesic, and antiplatelet effects [10]. In addition to the 
above, early evidence suggests there are beneficial effects of aspirin in preclinical and clinical studies in cancer prevention $[11,12]$, immune system [13], and mental illness [14], for instance. In view of this, the potential clinical importance of aspirin probably goes beyond our imagination.

To date, very few studies have addressed the role of aspirin in acute pancreatitis. Akyazi et al. [15] reported that longterm ASA pretreatment could prevent and/or ameliorate certain hematological, serological, and histological alterations caused by caerulein (Cae) induced AP. However, the specific role of aspirin in acute pancreatitis has not been elucidated and whether aspirin can protect against acinar cells necrosis is not clear. Collectively, this study was designed to investigate the role of aspirin in a SAP experimental model induced by Cae combined with Lipopolysaccharide (LPS).

\section{Materials and Methods}

2.1. Animals. Female ICR mice, weighing between 23 and $26 \mathrm{~g}$, were obtained from Vital River Company (Beijing, China). Before experiment, the animals were fed standard rodent chow and water, monitored in a controlled temperature and under a $12 \mathrm{~h}$ light/dark cycle for at least a week. The Principles of Laboratory Animal Care (NIH publication number 85Y23, revised 1996) were followed, and the experimental protocol was approved by the Animal Care Committee, Peking University Health Science Center (LA2010-059).

2.2. Induction of SAP and Experimental Design. Mice were injected with 7 doses of Cae $(50 \mu \mathrm{g} / \mathrm{kg}$, Ana Spec, Inc., San Jose, CA, USA) at 1-hour intervals intraperitoneally; then intraperitoneal injection with LPS $(7.5 \mathrm{mg} / \mathrm{kg}$, Santa Cruz, CA, USA) was carried out one hour later, to induce SAP model.

Animals were randomly assigned to 4 groups (each group had 8-12 mice): control, SAP, L-ASA, and $\mathrm{H}$-ASA. The mice in control group mice were given saline $(0.9 \% \mathrm{NaCl})$ solution intraperitoneally instead of Cae and LPS. Aspirin (SigmaAldrich, St. Louis, MO) suspension liquids were prepared in $0.5 \%$ of carboxyl methyl cellulose sodium (CMC-Na, Kemiou Chemical Reagent Corp, Tianjin, China). Two doses of aspirin $(12.5 \mathrm{mg} / \mathrm{kg}, 125 \mathrm{mg} / \mathrm{kg})$ were used to pretreat SAP, based on average human body weight of $60 \mathrm{~kg}$, and these doses correspond to approximately $100 \mathrm{mg}$ and $1000 \mathrm{mg}$ per day in human, respectively $[15,16]$. Vehicle (CMC-Na) or aspirin was administered $1 \mathrm{~h}$ before the first Cae injection.

2.3. Sample Collection and Preparation. Animals were sacrificed under anesthesia by intraperitoneal injection of pentobarbital sodium at $24 \mathrm{~h}$, until the onset of anesthesia; their pancreas and lung were dissected immediately. Blood samples were collected before and 12 and 24 hours after first Cae injection for amylase and lipase analysis. A portion of the pancreas and lung was fixed in $4 \%$ paraformaldehyde in phosphatebuffered saline (PBS, pH 7.4) for $12 \mathrm{~h}$ for histological analysis. The rest of the portion of pancreas and lung was stored at $-80^{\circ} \mathrm{C}$ for further investigation.
TABLE 1: Primer sequences for RT-PCR.

\begin{tabular}{lcc}
\hline Primer & & Sequence $\left(5^{\prime}\right.$ to $\left.3^{\prime}\right)$ \\
\hline \multirow{2}{*}{ TNF- $\alpha$} & Forward & CTGTGAAGGGAATGGGTGT \\
& Reverse & CAGGGAAGAATCTGGAAAGGTC \\
\multirow{2}{*}{ IL-6 } & Forward & TTCTTGGGACTGATGCTG \\
& Reverse & CTGGCTTTGTCTTTCTTGTT \\
\multirow{2}{*}{$18 \mathrm{~S}$} & Forward & GGAAGTGCACCACCAGGAGT \\
& Reverse & TGCAGCCCCGGACATCTAAG \\
\hline
\end{tabular}

2.4. Myeloperoxidase (MPO) and Cyclooxygenase (COX) Assay. To carry out the assays, pancreas tissue samples were thawed and homogenized in normal saline. The tissue homogenate was assayed for MPO activity and COX-1 and COX-2 level with test kits. All procedures were followed in accordance with the manufacturer's instructions (Nanjing Jiancheng Corp, Nanjing, China).

2.5. Serum Amylase and Lipase Assay. Blood was obtained by retroorbital bleed. Serum amylase and lipase were determined by using enzymatic methods. Activity of lipase and amylase was determined using lipase kits (Nanjing Jiancheng Corp., Nanjing, China) and amylase kits (Zhongsheng Beikong Bio-Technology, Beijing, China). All procedures were done in accordance with the manufacturer's instructions.

2.6. Histological Examination. Pancreas and lung tissue samples were fixed in $4 \%$ phosphate-buffered formaldehyde, embedded in paraffin blocks, stained with hematoxylin and eosin, and examined with a light microscope. The histopathological scoring analysis of pancreas and lung was performed blindly by two pathologists according to previously described methods $[17,18]$.

2.7. Real-Time Reverse Transcriptase-PCR (RT-PCR). Total RNA was extracted from pancreas tissue using the Trizol reagent (Invitrogen, USA) according to the manufacturer's instructions. The extracted total RNAs were dissolved in diethylpyrocarbonate (DEPC) water and stored at $-80^{\circ} \mathrm{C}$. RNA was reverse-transcribed using a RT kit (Invitrogen, USA). The specificity of the primers was confirmed using the BLAST program. All samples were quantitated by using the comparative CT method for relative quantitation of gene expression, normalized to $18 \mathrm{~S}$. The primer sequences used to amplify mRNAs were shown in Table 1.

2.8. Immunohistochemistry. The mentioned antibodies were purchased from Santa Cruz Biotechnology (Santa Cruz, California, USA). In brief, formalin-fixed, paraffin-embedded samples were cut into $5 \mu \mathrm{m}$ sections and each tissue section was deparaffinized and rehydrated with graded ethanol. The tissue was placed in EDTA antigen repairing buffer $(\mathrm{PH} \mathrm{8.0)}$ for antigen retrieval in the microwave oven. After natural cooling, tissues were put in phosphate-buffered saline (PBS) at $\mathrm{pH} 7.4$ three times, each time for $5 \mathrm{~min}$. Then tissues were incubated at room temperature for 25 minutes in the dark 

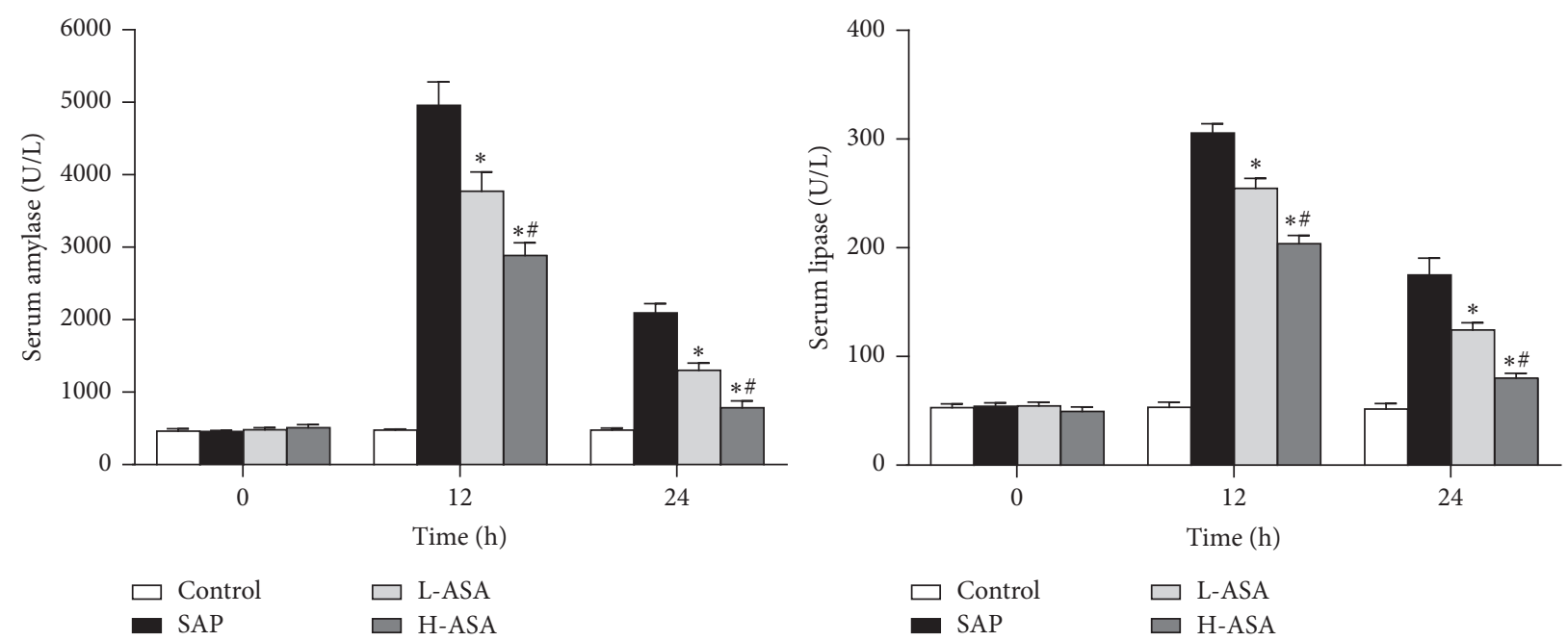

FIGURE 1: Effect of aspirin on serum amylase and lipase levels in SAP. Blood samples were collected before and 12 and 24 hours after first Cae injection for amylase and lipase analysis. Data are represented as mean $\pm \mathrm{SD}\left(n=8--12\right.$ per group). ${ }^{*} P<0.05$ versus $\mathrm{SAP}$ group, ${ }^{\#} P<0.05$ versus L-ASA group.

with $3 \%$ hydrogen peroxide solution. Slides were incubated overnight at $4^{\circ} \mathrm{C}$ in a humid chamber with an antibody against MPO (1:100 dilution), NF- $\kappa$ B p65 (1:100 dilution), Bax (1:200 dilution), Bcl-2 (1:500 dilution), and caspase 3 ( $1: 300$ dilution). Then tissues were incubated by biotinylated secondary antibody (1:200 dilution) for $50 \mathrm{~min}$. Finally, sections were counterstained with hematoxylin. The slides were observed under a light microscope. Immunohistochemistry and quantitative analysis of protein expression is according to previously described methods $[19,20]$.

2.9. Western Blot (WB). Briefly, pancreatic samples were homogenized in ice-cold radioimmunoprecipitation assay (RIPA, Beyotime Biotechnology, Beijing, China) buffer containing $1 \mathrm{mmoL} / \mathrm{L}$ phenylmethanesulfonyl fluoride (PMSF, Beyotime Biotechnology, Beijing, China) and a cocktail of protease inhibitors (1:100 dilution, Roche, Shanghai, China). Protein concentrations were determined using the BCA method (Thermo Fisher Scientific, MA, USA). Equal amounts of protein $(50 \mu \mathrm{g})$ per lane were separated by $10 \%$ sodium dodecyl sulfate-polyacrylamide gel electrophoresis and transferred to polyvinylidene difluoride (PVDF) membranes. The membrane was blocked by $5 \%(\mathrm{w} / \mathrm{v})$ bull serum albumin (BSA, Biosharp, Beijing, China) in Trisbuffered saline $/ 0.05 \%$ Tween-20 (TBST) at room temperature for $2 \mathrm{~h}$ in a covered container and incubated overnight at $4^{\circ} \mathrm{C}$ with primary antibodies against receptor-interacting serine/threonine-protein kinase (RIP) 1 and 3 protein $(1: 1000$ dilution, CST, MA, USA), and phospho-mixed lineage kinase domain-like protein (p-MLKL, 1:1000 dilution, Abcam, Hong Kong, China) in blocking buffer. On the next day membranes were washed with TBST $(3 \times 10 \mathrm{~min})$ and incubated with a secondary goat anti-mouse or goat anti-rabbit IgG horseradish peroxidase (HRP) antibody (1:10000 dilution, Sigma-Aldrich Co., St. Louis. MO, USA) diluted in 5\% (w/v) dry nonfat milk in TBST for $1 \mathrm{~h}$ at room temperature. Finally, membranes were washed with TBST $(3 \times 10 \mathrm{~min})$, developed using the ECL detection system (Santa Cruz Biotechnology), quickly dried, and exposed to ECL flm.

2.10. Quantification of Apoptosis. Apoptosis was quantified on pancreatic tissue by the terminal deoxynucleotidyl transferase-mediated dUTP-biotin nick end labeling (TUNEL, Roche, Shanghai, China) assay. Briefly, sections of $5 \mu \mathrm{m}$ thickness were prepared from pancreas. Sections were stained according to the manufacturer's protocol and examined with light microscopy. The apoptosis index was calculated as the percentage of stained cells, as described previously [21].

2.11. Statistical Analyses. Results are presented as the mean \pm SD. The Kruskal-Wallis test followed by the Mann-Whitney $U$ test was used to evaluate the differences in histopathologic scores. Statistical analysis was performed using one-way ANOVA followed by the Student-Newman-Keuls test as a post hoc test. A value of $P<0.05$ was considered statistically significant. Statistical analysis was finished by the SPSS 13.0 statistical program.

\section{Results}

3.1. Aspirin Reduced Serum Amylase and Lipase Levels and Alleviated the Histopathological Alterations of the Pancreas in SAP in Mice. Serum amylase and lipase are most commonly obtained as biochemical markers of AP, so we assessed the severity of SAP by measuring the levels of these enzymes. As shown in Figure 1, aspirin significantly reduced the levels of amylase and lipase in serum.

We investigated the histopathological alterations of the pancreas after administration of Cae and LPS. In control group, the histological features of the pancreas were typical of normal pancreatic architecture. Compared with the SAP 

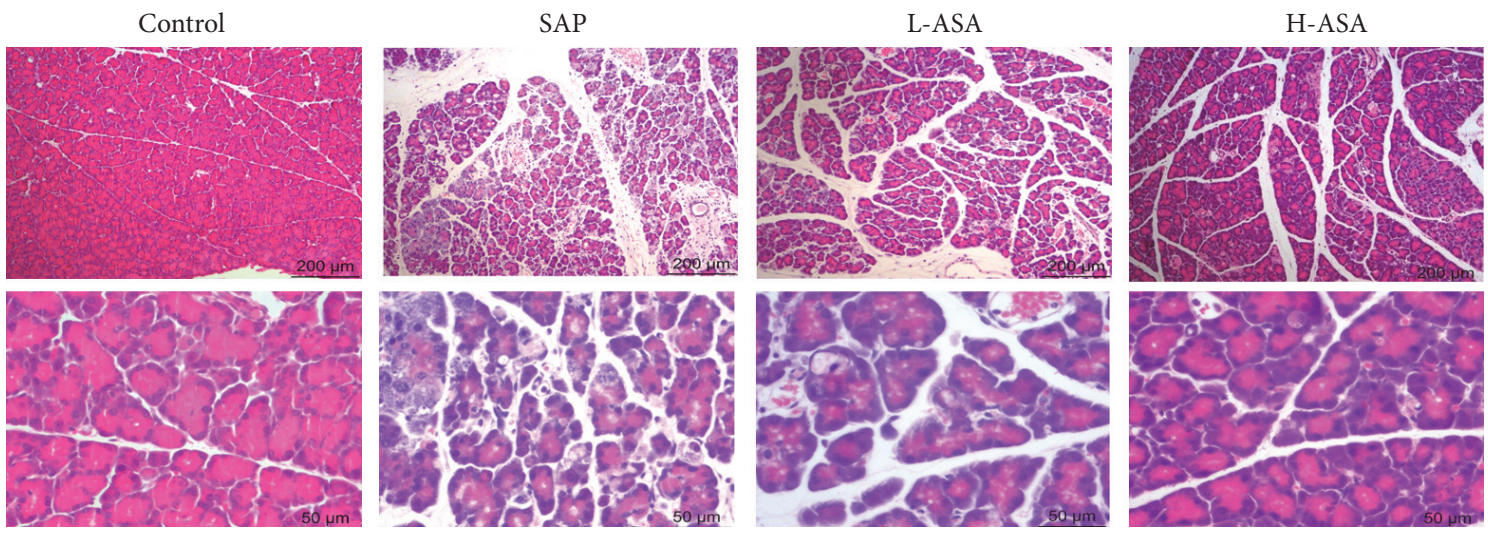

(a)
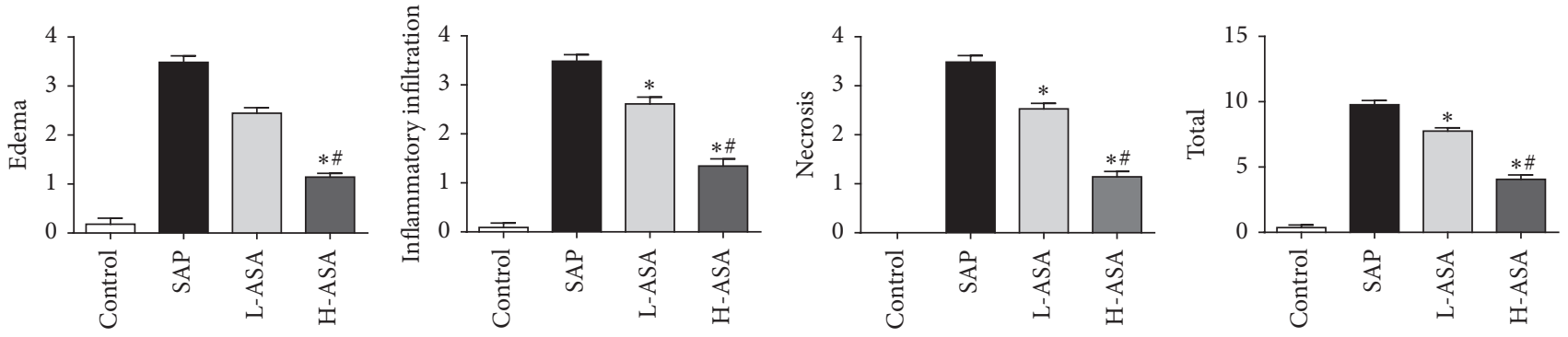

(b)

FIgURE 2: Effect of aspirin on pancreas histology in SAP. Pancreas was dissected 24 hours after first Cae injection. (a) Representative HE staining and (b) histological scores of pancreas are shown. ${ }^{*} P<0.05$ versus SAP group, ${ }^{\sharp} P<0.05$ versus L-ASA group.

group, we found that pretreatment with aspirin markedly reduced the histological features of pancreatic injury in LASA and H-ASA group, characterized as lower degree of edema, less inflammatory cell infiltration, and alleviated acinar cell necrosis. Additionally, the high-dose aspirin pretreatment was more effective than the low-dose aspirin pretreatment (Figures 2(a) and 2(b)).

3.2. Aspirin Decreased the MPO Activity of Pancreas in SAP Mice. MPO activity in the pancreas was examined to evaluate the neutrophil infiltration into the damaged tissue. As shown in Figure 3, mice with SAP showed increased MPO activity in pancreas; however, aspirin significantly reduced the MPO activity in pancreas (Figure 3(c)). Similar changes were also observed at the immunohistochemical staining of MPO in pancreatic tissue (Figures 3(a) and 3(b)).

The level of proinflammatory cytokines was used to evaluate the degree of AP, involved in the aggravation of AP. In the murine model of SAP, as expected, we found that the mRNA expression of IL- 6 and TNF- $\alpha$ in pancreatic tissue was significantly upregulated but reduced after aspirin treatment (Figures $4(\mathrm{a})$ and $4(\mathrm{~b})$ ). The activation of NF- $\kappa \mathrm{B}$ plays a key role in the induction of several proinflammatory mediators. The nuclear translocation of the NF- $\kappa \mathrm{B}$ transcription factor is the hallmark of signal pathway activation. In identification of inflammatory pathways in the pathogenesis of aspirin on the role of SAP, we examined the expression level of NF- $\kappa$ B p 65 by immunohistochemical staining. As shown in Figure 4, aspirin reduced NF- $\kappa \mathrm{B}$ p 65 nuclear protein expression in pancreas (Figures 4(c) and 4(d)).

3.3. Aspirin Induced Acinar Cells Apoptosis and Alleviated the Expression of $\mathrm{Bax}, \mathrm{Bcl}-2$, and Caspase 3. The apoptosis of acinar cells was analyzed by TUNEL staining. As shown in Figures 5(a) and 5(b), Cae combined with LPS could induce pancreatic acinar cells apoptosis. And compared with the SAP group, the number of TUNEL-positive cells was significantly increased by the treatment of aspirin. Compared with the SAP group, the mRNA and protein expression levels of Bax and caspase 3 were significantly higher, and those of Bcl-2 were significantly lower in the ASA group (Figures 5(c)-5(e)).

3.4. Aspirin Reduced the Expression of RIP1, RIP3, and p$M L K L$ in Pancreas of Mice with SAP. Recent study indicated that necrosis was also regulated by programmed pathways which was similar with apoptosis, and this programmed cell necrosis indeed existed in acute pancreatitis [22-25]. According to the pancreatic $\mathrm{H} \& \mathrm{E}$ stain, we observed that aspirin remarkably alleviated the necrosis of pancreatic acinar cells (Figures 2(a) and 2(b)). We further adopted Western Blot to examine the alterations of RIP1, RIP3, and p-MLKL protein levels in pancreatic tissue; amazingly, the expressions of RIP1, RIP3, and p-MLKL were significantly reduced in 


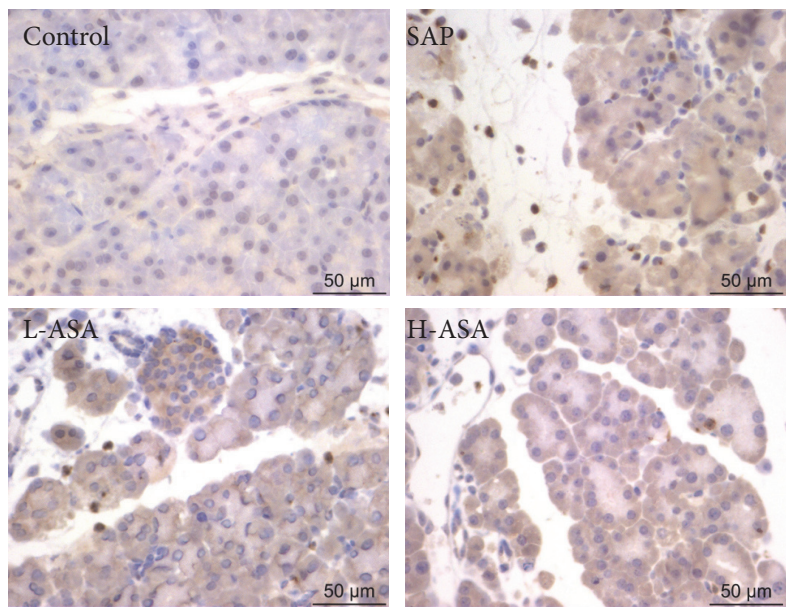

(a)

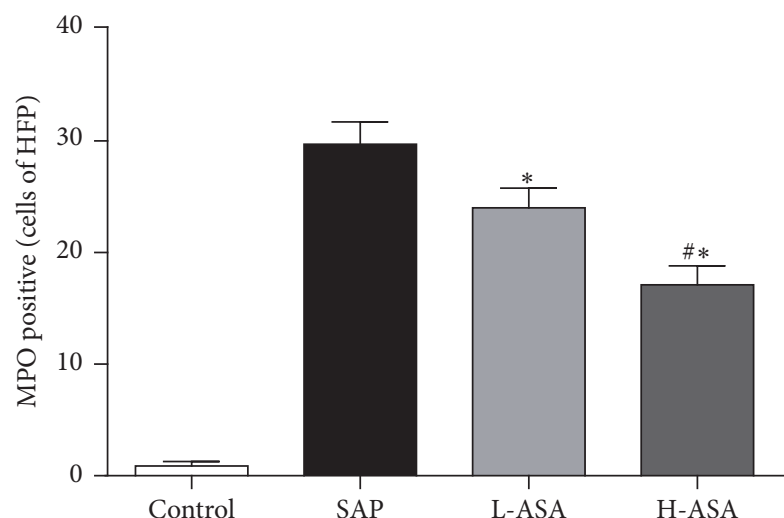

(b)

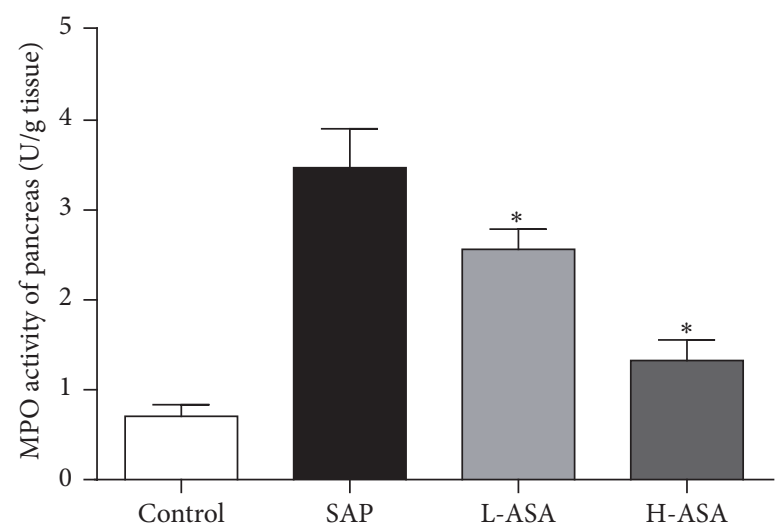

(c)

FIGURE 3: Effect of aspirin on the neutrophil infiltration in pancreas. MPO activity in the pancreas was examined to evaluate the neutrophil infiltration into the damaged tissue. (a) Representative Immunohistochemistry images for Myeloperoxidase (MPO) in the pancreas. (b) The frequencies of MPO positive cell in pancreas. (c) MPO activity of pancreas. ${ }^{*} P<0.05$ versus SAP group, ${ }^{*} P<0.05$ versus L-ASA group.

aspirin administration group and it was consistent with the pathological results in Figure 6.

\subsection{Aspirin Reduced the COX-1 and COX-2 Level of Pancreas} in SAP Mice. Aspirin is a kind of NASIDs and it could restrain the activity of cyclooxygenase (COX). In our study, we have verified that aspirin had effects on cyclooxygenase and our results showed that, after Cae joint LPS administration, COX-1 slightly increased while COX-2 elevated dramatically in comparison with the control mice. At the same time, after aspirin intervention, the activities of COX1 and COX-2 were inhibited to different degrees compared with the SAP model mice, as shown in Figure 7.

3.6. Aspirin Alleviated the Histopathological Alterations of the Lung. Acute lung injury (ALI) is one of the most common complications of SAP. Therefore, we detected the degree of ALI in mice with SAP as a supplement in this experiment. Results showed that the histological features of lung injury in SAP were markedly reduced with aspirin pretreatment, characteristic as lower thickness of alveolar, less neutrophils infiltration, and alleviated alveolar congestion, as shown in Figure 8.

\section{Discussion}

In this study, we for the first time confirmed that aspirin could remarkably alleviate the severity of SAP and protects against acinar cells necrosis by downregulation of RIP1, RIP3, and $\mathrm{p}$-MLKL expressions. In murine model, SAP and its associated lung injury induced by Cae joint LPS injection are similar to the clinical manifestations of human SAP and lung damage $[26,27]$. In our present study, we investigated the effect of aspirin in a model of SAP and associated lung injury in mice. Our observation demonstrated that aspirin significantly alleviated the pancreatic damage in SAP and associated lung injury, as shown by the results of histological characteristics, MPO activity, and serum amylase and lipase levels (Figures 1-3 and 8). In addition, aspirin inhibited the nuclear protein expression of NF- $\kappa \mathrm{B}$ p 65 in acinar cell and the mRNA expression levels of TNF- $\alpha$ and IL- 6 in the pancreas (Figure 4), which was critical for the local tissue 


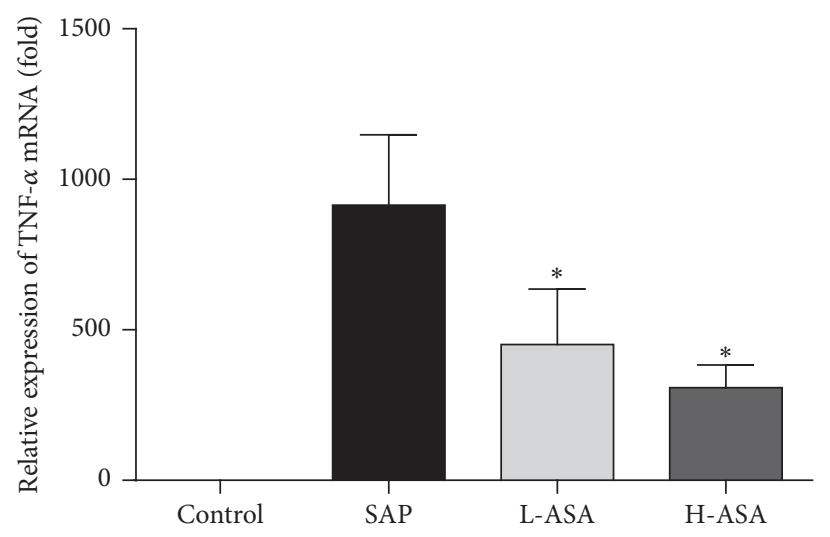

(a)

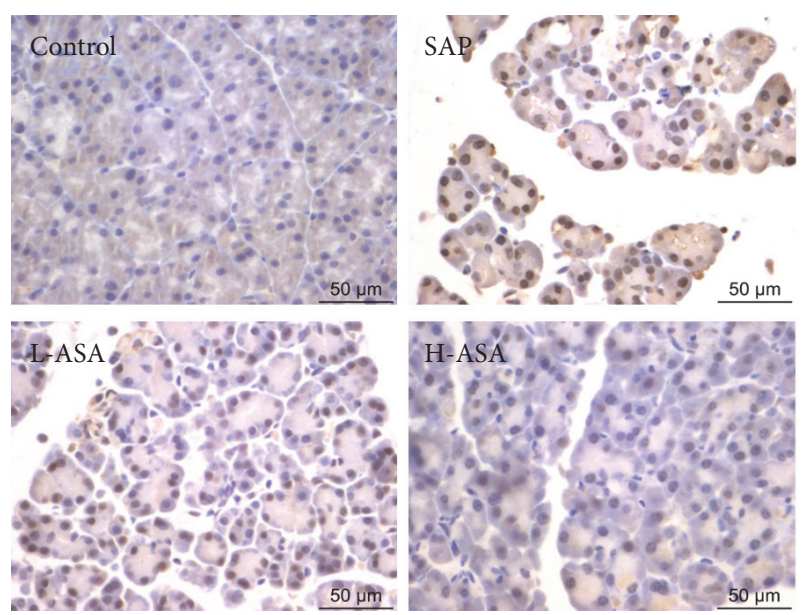

(c)

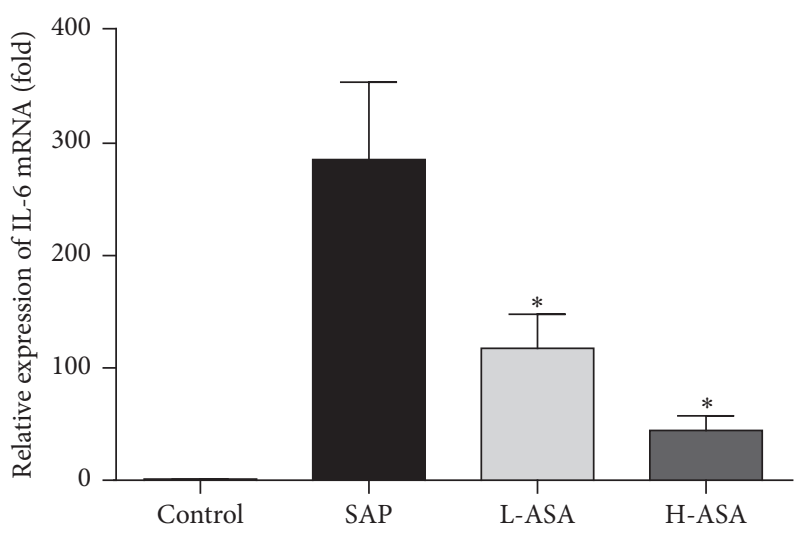

(b)

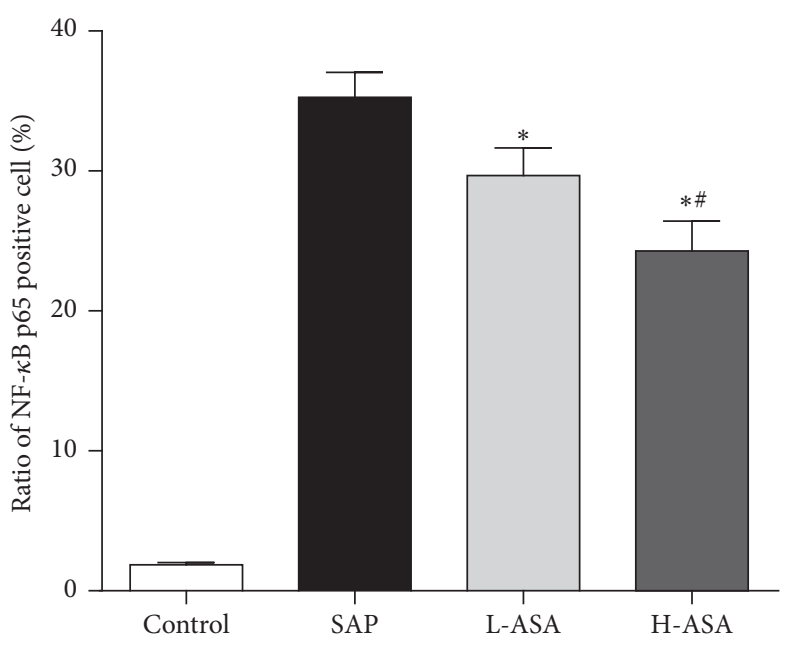

(d)

FIGURE 4: Anti-inflammatory effect of aspirin in SAP. The mRNA expression of proinflammatory cytokines TNF- $\alpha$ (a) and IL-6 (b) was detected by RT-PCR. 18S was used as the internal reference for total tissue proteins. (c) Representative Immunohistochemistry images for NF $\kappa$ B p 65 in the pancreas. (d) The frequencies of MPO positive cell in pancreas. ${ }^{*} P<0.05$ versus SAP group, ${ }^{\#} P<0.05$ versus L-ASA group.

injury expanding to the systemic inflammatory responses in AP.

Apoptosis and necrosis have a significant impact on the pathogenesis of AP. In the early stage of AP, various factors could cause pancreatic acinar cell injury/death; thus acinar cells necrosis would increase the intracellular activity of trypsin of pancreatic tissue, releasing various inflammatory mediators and triggering inflammation cascade. However, apoptosis of acinar cells would reduce the release and activity of trypsin and alleviate inflammation cascade. Hence, it is generally recognized that necrosis is the initiator of inflammation, and apoptosis has a protective effect on acinar cell $[26,28]$.

Aspirin has been shown to promote apoptosis and regulated the expression of Bax, Bcl-2, in other cells types [29, 30]. In our study, aspirin promoted acinar cell apoptosis by TUNEL staining (Figures 5(a) and 5(b)), and the results of immunohistochemistry and RT-PCR show that aspirin significantly suppressed the expression of $\mathrm{Bcl}-2$ and upregulated the expression of Bax (Figures 5(c)-5(e)); of note, aspirin further increased caspase 3 protein expression in acinar cells, and such upregulation was correlated positively with acinar cell apoptosis and protection against acinar cell necrosis. Furthermore, high dose of aspirin group showed better protective effect than low dose of aspirin.

In the past, programmed cell death was thought to occur only in apoptosis. This form of cell death is characterized by induced changes that minimize its impact on neighboring living cells. Recent findings have revealed, however, that, another form of death, necrosis can also be dictated by defined molecular pathways, one of which involving RIP1, RIP3, and p-MLKL as key molecules, and this kind of programmed necrosis is named necroptosis [31-33]. It was found that the necrosis of pancreatic acinar cell in Cae induced AP model in RIP3 defect mice or MLKL defect mice was significantly decreased in comparison with wild type mice $[23,34,35]$, which indicated that necroptosis played an important role in AP. To our knowledge, there was no study at present focusing on the effects of aspirin on necroptosis pathways. In our study, we adopted Western Blot to observe that aspirin obviously reduced the expressions of RIP1, RIP3, and $\mathrm{p}$-MLKL for the first time and it was consistent with the 


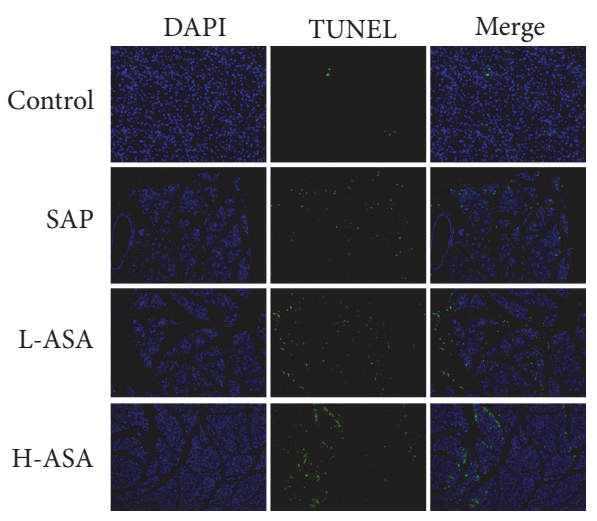

(a)

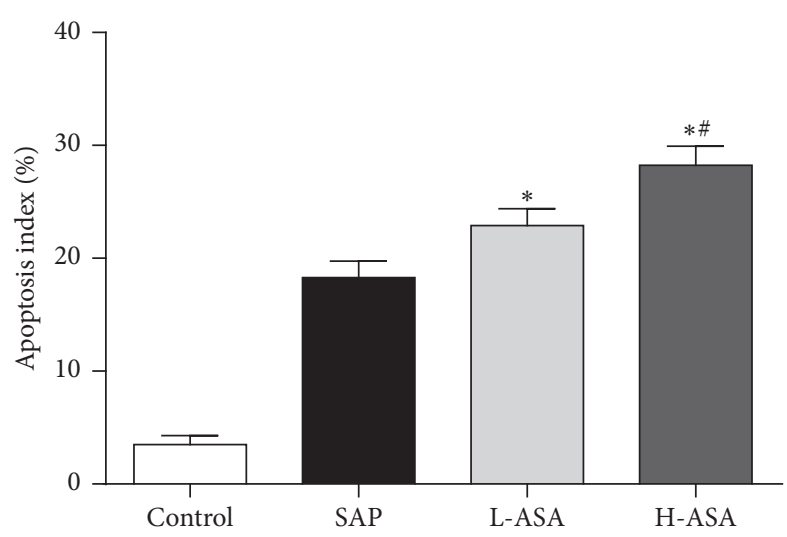

(b)

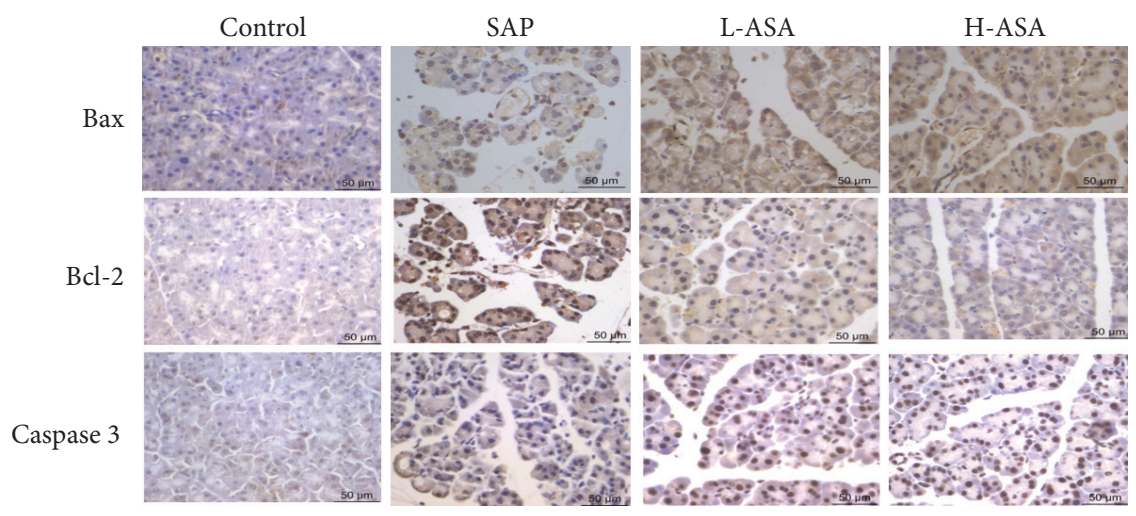

(c)

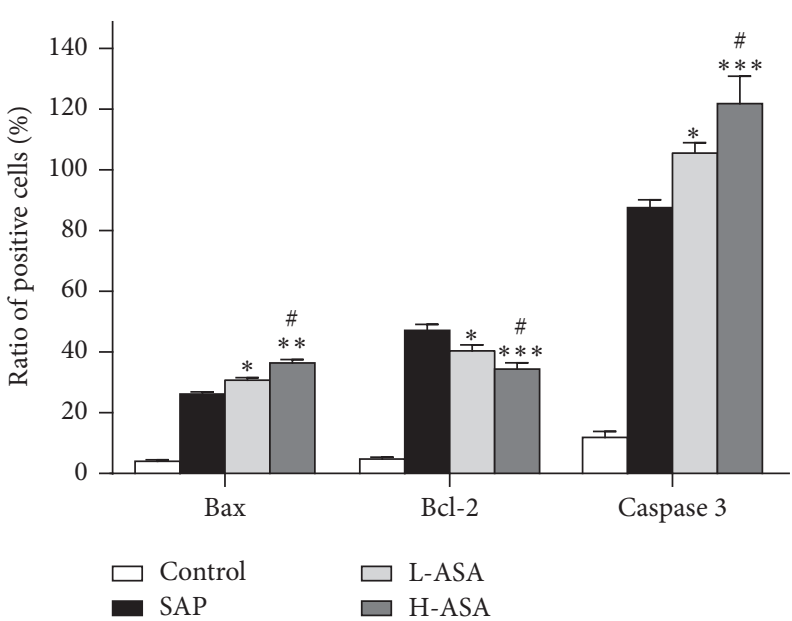

(d)

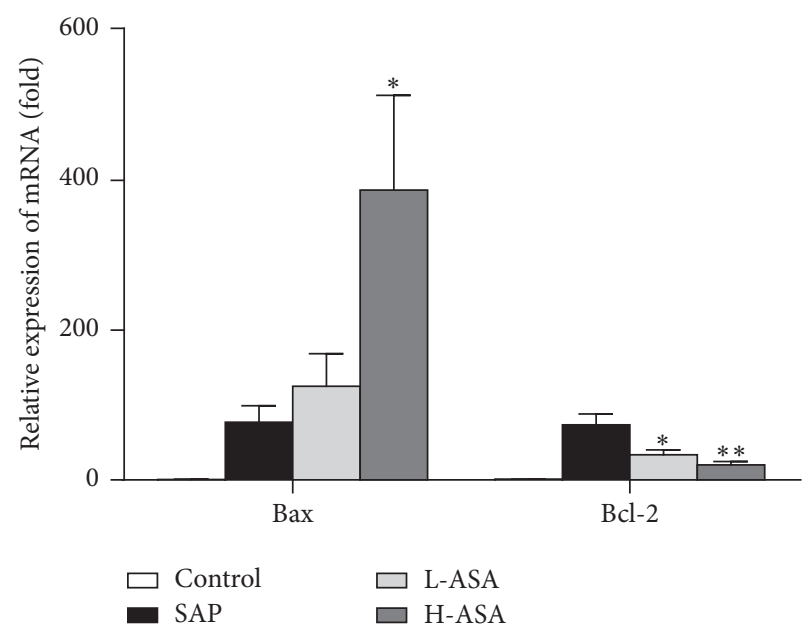

(e)

FIGURE 5: Effect of aspirin on apoptosis of acinar cells in SAP. The apoptosis of acinar cells was analyzed by TUNEL staining. (a) Representative Immunohistochemistry images for TUNEL staining. (b) The frequencies of TUNEL-positive cell in pancreas. The mRNA (c) and protein (d, e) expression levels of Bax, Bcl-2, and caspase 3 in pancreas. ${ }^{*} P<0.05,{ }^{* *} P<0.01$, and ${ }^{* * *} P<0.001$ versus SAP group, ${ }^{*} P<0.05$ versus L-ASA group.

results of H\&E stain (Figure 6). Collectively, we speculated that aspirin protected pancreatic acinar cells against necrosis via impairing necroptosis pathways by downregulated expression of RIP1, RIP3, and p-MLKL.

In addition, aspirin is a cyclooxygenase inhibitor and mainly inhibits the activity of COX-1 as well as COX-2 at some times. As we know, COX-1 is fundamentally expressed in various organs while COX-2 is inducible expression and a variety of traumatic chemical, physical, and biological factors can activate the expression of COX-2. Previous study has found that COX-2 played an important role in the pathogenesis of AP and the inhibition of COX-2 could 


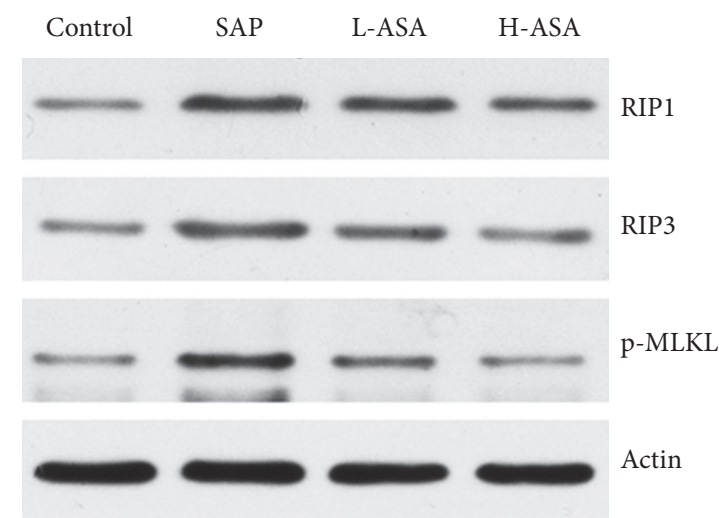

(a)

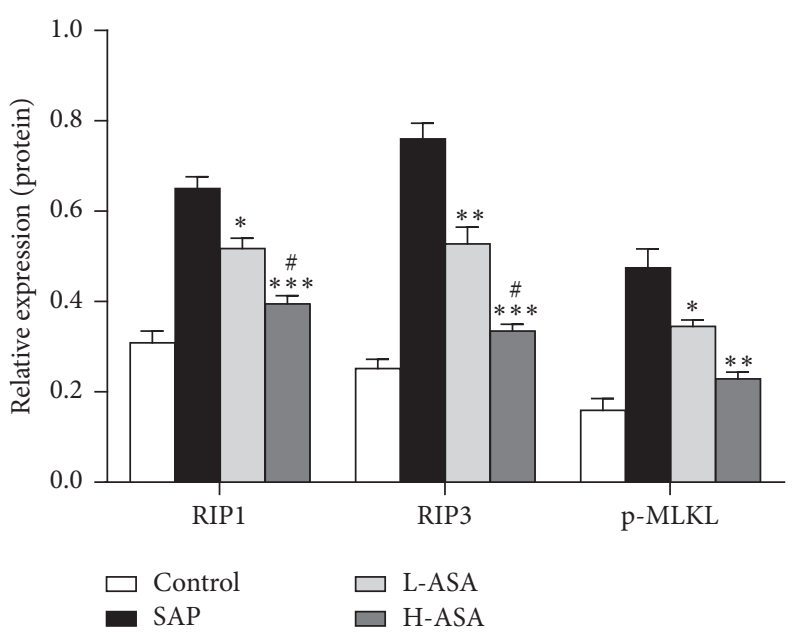

(b)

FIGURE 6: Effect of aspirin on necrosis pathway of pancreatic acinar cells in SAP. (a) RIP1, RIP3, and p-MLKL expressions detected by Western Blot analysis. (b) Relative protein expression of RIP1, RIP3, and p-MLKL. ${ }^{*} P<0.05,{ }^{* *} P<0.01$, and ${ }^{* * *} P<0.001$ versus SAP group, ${ }^{\#} P<0.05$ versus L-ASA group.
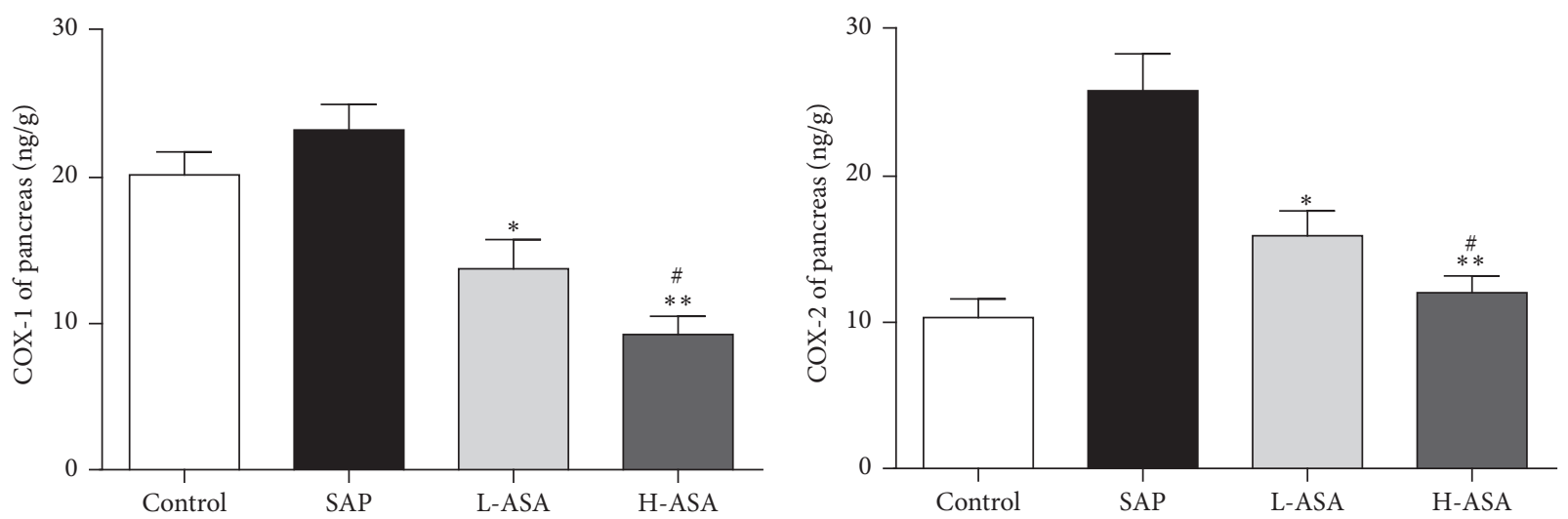

FIgURE 7: Effect of aspirin on COX-1 and COX-2 level of pancreas in SAP. Pancreatic tissues were collected 24 hours after first Cae injection for COX-1 and COX-2 analysis. Data are represented as mean $\pm \mathrm{SD}\left(n=8\right.$ per group). ${ }^{*} P<0.05,{ }^{* *} P<0.01$ versus $\mathrm{SAP}$ group, ${ }^{*} P<0.05$ versus L-ASA group.

markedly alleviate the inflammatory response in AP mice [36-41]. Our results indicated that, after the induction of SAP model by Caerulein combined with LPS, the level of COX-1 in pancreatic tissue was not elevated obviously while the level of COX-2 increased by 2.5 times and this was in accordance with the physiological function of them. In our study, it was observed that aspirin could decrease the level of COX-1 and COX-2 in a dose-dependent manner (Figure 7), which on the one hand confirmed the pharmacological effects of aspirin as NASIDs and on the other hand proved that aspirin alleviated the inflammatory responses and protected against acinar cell injury by inhibiting COX-2 in AP.

Taken together, our study showed that aspirin could reduce the severity of SAP and protect pancreatic acinar cell against necrosis in mice. It is possible that aspirin may be a promising clinical therapeutic strategy for the treatment of SAP in future.

\section{Competing Interests}

All authors of this paper have no conflict of interests to disclose.

\section{Authors' Contributions}

Guotao Lu and Zhihui Tong contributed equally to this work.

\section{Acknowledgments}

Special thanks are due to Professor Wei Huang for her critical review and expert technical assistance. This study is supported by National Natural Science Foundation of China (no. 81170438 and no. 81300360), the National Natural Science Foundation of Yangzhou City (SQN20140063), the Postdoctoral Science Foundation of China (2014M562664), 

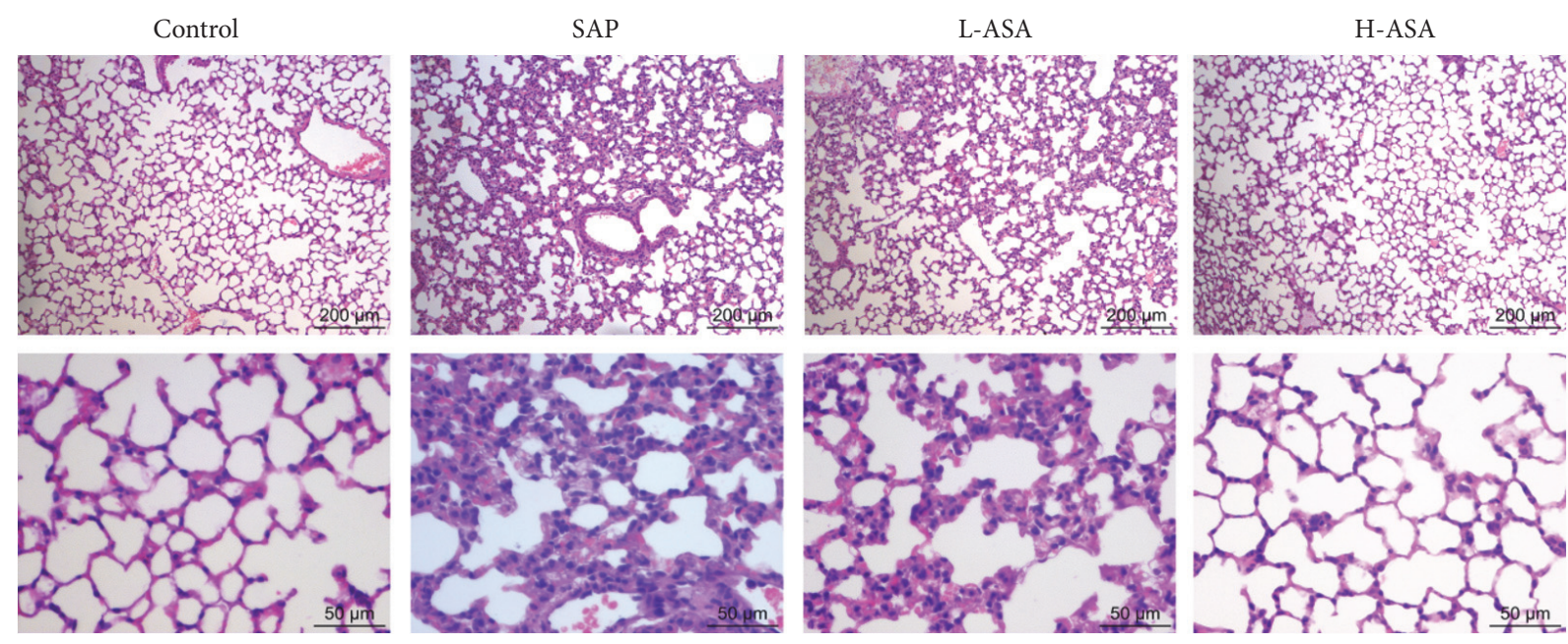

(a)
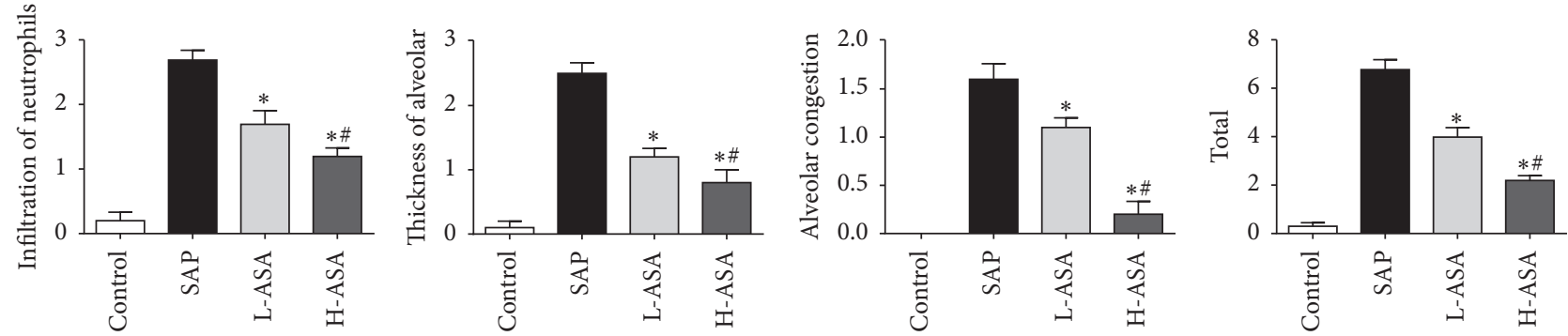

(b)

FIGURE 8: Effect of aspirin on lung histology in SAP. Lung was dissected 24 hours after first caerulein injection. (a) Representative HE staining and (b) histological scores of lung are shown. ${ }^{*} P<0.05$ versus SAP group, ${ }^{\#} P<0.05$ versus L-ASA group.

and the Laboratory Animal Platform Project of Zhejiang Provincial Science and Technology Agency (2013C37022).

\section{References}

[1] P. G. Lankisch, M. Apte, and P. A. Banks, "Acute pancreatitis," The Lancet, vol. 386, no. 9988, pp. 85-96, 2015.

[2] E. Afghani, S. J. Pandol, T. Shimosegawa et al., "Acute pancreatitis-progress and challenges: a report on an international symposium," Pancreas, vol. 44, no. 8, pp. 1195-1210, 2015.

[3] E. Zerem, "Treatment of severe acute pancreatitis and its complications," World Journal of Gastroenterology, vol. 20, no. 38, pp. 13879-13892, 2014.

[4] M. S. Petrov, S. Shanbhag, M. Chakraborty, A. R. J. Phillips, and J. A. Windsor, "Organ failure and infection of pancreatic necrosis as determinants of mortality in patients with acute pancreatitis," Gastroenterology, vol. 139, no. 3, pp. 813-820, 2010.

[5] O. Meyrignac, S. Lagarde, B. Bournet et al., "Acute pancreatitis: extrapancreatic necrosis volume as early predictor of severity," Radiology, vol. 276, no. 1, pp. 119-128, 2015.

[6] O. J. Bakker, H. C. van Santvoort, M. G. H. Besselink, E. Harst, H. S. Hofker, and H. G. Gooszen, "Prevention, detection, and management of infected necrosis in severe acute pancreatitis," Current Gastroenterology Reports, vol. 11, no. 2, pp. 104-110, 2009.

[7] S. L. M. Das, J. I. C. Kennedy, R. Murphy, A. R. J. Phillips, J. A. Windsor, and M. S. Petrov, "Relationship between the exocrine and endocrine pancreas after acute pancreatitis," World Journal of Gastroenterology, vol. 20, no. 45, pp. 17196-17205, 2014.

[8] M. Vujasinovic, B. Tepes, J. Makuc et al., "Pancreatic exocrine insufficiency, diabetes mellitus and serum nutritional markers after acute pancreatitis," World Journal of Gastroenterology, vol. 20, no. 48, pp. 18432-18438, 2014.

[9] T.-W. Ho, J.-M. Wu, T.-C. Kuo et al., "Change of both endocrine and exocrine insufficiencies after acute pancreatitis in non-diabetic patients: a nationwide population-based study," Medicine (Baltimore), vol. 94, no. 27, p. el123, 2015.

[10] J. Y. Wick, "Aspirin: a history, a love story," Consultant Pharmacist, vol. 27, no. 5, pp. 322-329, 2012.

[11] P. M. Rothwell, J. F. Price, F. G. R. Fowkes et al., "Short-term effects of daily aspirin on cancer incidence, mortality, and nonvascular death: analysis of the time course of risks and benefits in 51 randomised controlled trials," The Lancet, vol. 379, no. 9826, pp. 1602-1612, 2012.

[12] L. Alfonso, G. Ai, R. C. Spitale, and G. J. Bhat, "Molecular targets of aspirin and cancer prevention," British Journal of Cancer, vol. 111, no. 1, pp. 61-67, 2014.

[13] M. Hussain, A. Javeed, M. Ashraf, Y. Zhao, M. M. Mukhtar, and M. U. Rehman, "Aspirin and immune system," International Immunopharmacology, vol. 12, no. 1, pp. 10-20, 2012.

[14] M. Berk, O. Dean, H. Drexhage et al., "Aspirin: a review of its neurobiological properties and therapeutic potential for mental illness," BMC Medicine, vol. 11, article 74, 2013. 
[15] I. Akyazi, E. Eraslan, A. Gülçubuk et al., "Long-term aspirin pretreatment in the prevention of cerulein-induced acute pancreatitis in rats," World Journal of Gastroenterology, vol. 19, no. 19, pp. 2894-2903, 2013.

[16] M. Kleiber, "Body size and metabolic rate," Physiological Reviews, vol. 27, no. 4, pp. 511-541, 1947.

[17] J. Liu, P. Xu, L. Zhang et al., "FTY720 attenuates acute pancreatitis in hypertriglyceridemic apolipoprotein CIII Transgenic mice," Shock, vol. 44, no. 3, pp. 280-286, 2015.

[18] F. A. Gultekin, M. Kerem, E. Tatlicioglu, A. Aricioglu, C. Unsal, and N. Bukan, "Leptin treatment ameliorates acute lung injury in rats with cerulein-induced acute pancreatitis," World Journal of Gastroenterology, vol. 13, no. 21, pp. 2932-2938, 2007.

[19] W. Xiao, K. Wu, M. Yin et al., "Wogonin inhibits tumor-derived regulatory molecules by suppressing STAT3 signaling to promote tumor immunity," Journal of Immunotherapy, vol. 38, no. 5, pp. 167-184, 2015.

[20] M. Cregger, A. J. Berger, and D. L. Rimm, "Immunohistochemistry and quantitative analysis of protein expression," Archives of Pathology and Laboratory Medicine, vol. 130, no. 7, pp. 10261030, 2006.

[21] G. Hu, J. Shen, L. Cheng et al., "Reg4 protects against acinar cell necrosis in experimental pancreatitis," Gut, vol. 60, no. 6, pp. 820-828, 2011.

[22] Y. Liu, L. Yang, K.-L. Chen et al., "Knockdown of GRP78 promotes apoptosis in pancreatic acinar cells and attenuates the severity of cerulein and LPS induced pancreatic inflammation," PLoS ONE, vol. 9, no. 3, Article ID e92389, 2014.

[23] J. M. Louhimo, M. L. Steer, and G. Perides, "Necroptosis is an important severity determinant and potential therapeutic target in experimental severe pancreatitis," CMGH Cellular and Molecular Gastroenterology and Hepatology, vol. 2, no. 4, pp. 519-535, 2016.

[24] X. Ma, D. J. Conklin, F. Li et al., "The oncogenic microRNA miR-21 promotes regulated necrosis in mice," Nature Communications, vol. 6, article 7151, 2015.

[25] Y. Liu, J. Yuan, T. Tan et al., "Genetic inhibition of protein kinase $\mathrm{C} \varepsilon$ attenuates necrosis in experimental pancreatitis," American Journal of Physiology-Gastrointestinal and Liver Physiology, vol. 307, no. 5, pp. G550-G563, 2014.

[26] O. A. Mareninova, K.-F. Sung, P. Hong et al., "Cell death in pancreatitis: caspases protect from necrotizing pancreatitis," Journal of Biological Chemistry, vol. 281, no. 6, pp. 3370-3381, 2006.

[27] A. S. Gukovskaya and S. J. Pandol, "Cell death pathways in pancreatitis and pancreatic cancer," Pancreatology, vol. 4, no. 6, pp. 567-586, 2004.

[28] A. M. Kaiser, A. K. Saluja, A. Sengupta, M. Saluja, and M. L. Steer, "Relationship between severity, necrosis, and apoptosis in five models of experimental acute pancreatitis," American Journal of Physiology-Cell Physiology, vol. 269, no. 5, pp. C1295-C1304, 1995.

[29] J.-H. Ding, L.-Y. Yuan, R.-B. Huang, and G.-A. Chen, "Aspirin inhibits proliferation and induces apoptosis of multiple myeloma cells through regulation of Bcl-2 and Bax and suppression of VEGF,' European Journal of Haematology, vol. 93, no. 4, pp. 329-339, 2014.

[30] Y. Tian, Y. Ye, W. Gao et al., "Aspirin promotes apoptosis in a murine model of colorectal cancer by mechanisms involving downregulation of IL-6-STAT3 signaling pathway," International Journal of Colorectal Disease, vol. 26, no. 1, pp. 13-22, 2011.
[31] L. Sun and X. Wang, "A new kind of cell suicide: mechanisms and functions of programmed necrosis," Trends in Biochemical Sciences, vol. 39, no. 12, pp. 587-593, 2014.

[32] W. Zhou and J. Yuan, "SnapShot: necroptosis," Cell, vol. 158, no. 2, p. 464.e1, 2014.

[33] L. Galluzzi, O. Kepp, and G. Kroemer, "RIP kinases initiate programmed necrosis," Journal of Molecular Cell Biology, vol. 1, no. 1, pp. 8-10, 2009.

[34] S. He, L. Wang, L. Miao et al., "Receptor interacting protein kinase-3 determines cellular necrotic response to TNF- $\alpha$," Cell, vol. 137, no. 6, pp. 1100-1111, 2009.

[35] J. Wu, Z. Huang, J. Ren et al., "Mlkl knockout mice demonstrate the indispensable role of Mlkl in necroptosis," Cell Research, vol. 23, no. 8, pp. 994-1006, 2013.

[36] D. F. Barbeiro, M. K. Koike, A. M. M. Coelho, F. P. da Silva, and M. C. C. Machado, "Intestinal barrier dysfunction and increased COX-2 gene expression in the gut of elderly rats with acute pancreatitis," Pancreatology, vol. 16, no. 1, pp. 52-56, 2016.

[37] G. Ozhan, T. H. Yanar, C. Ertekin, and B. Alpertunga, “The effect of genetic polymorphisms of cyclooxygenase 2 on acute pancreatitis in Turkey," Pancreas, vol. 39, no. 3, pp. 371-376, 2010.

[38] S.-W. Seo, W.-S. Jung, T.-G. Piao et al., "Selective cyclooxygenase-2 inhibitor ameliorates cholecystokinin-octapeptideinduced acute pancreatitis in rats," World Journal of Gastroenterology, vol. 13, no. 16, pp. 2298-2304, 2007.

[39] E. Alhan, N. I. Kalyoncu, C. Ercin, and B. V. Kural, "Effects of the celecoxib on the acute necrotizing pancreatitis in rats," Inflammation, vol. 28, no. 5, pp. 303-309, 2004.

[40] W.-W. Yan, Z.-G. Zhou, Y.-D. Chen, and H.-K. Gao, "Role of COX-2 in microcirculatory disturbance in experimental pancreatitis," World Journal of Gastroenterology, vol. 10, no. 14, pp. 2095-2098, 2004.

[41] J. L. J. De Almeida, J. Jukemura, A. M. M. Coelho, R. A. Patzina, M. C. C. Machado, and J. E. M. D. Cunha, "Inhibition of cyclooxygenase- 2 in experimental severe acute pancreatitis," Clinics, vol. 61, no. 4, pp. 301-306, 2006. 


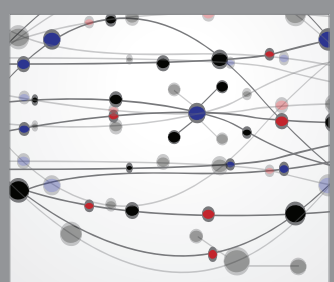

The Scientific World Journal
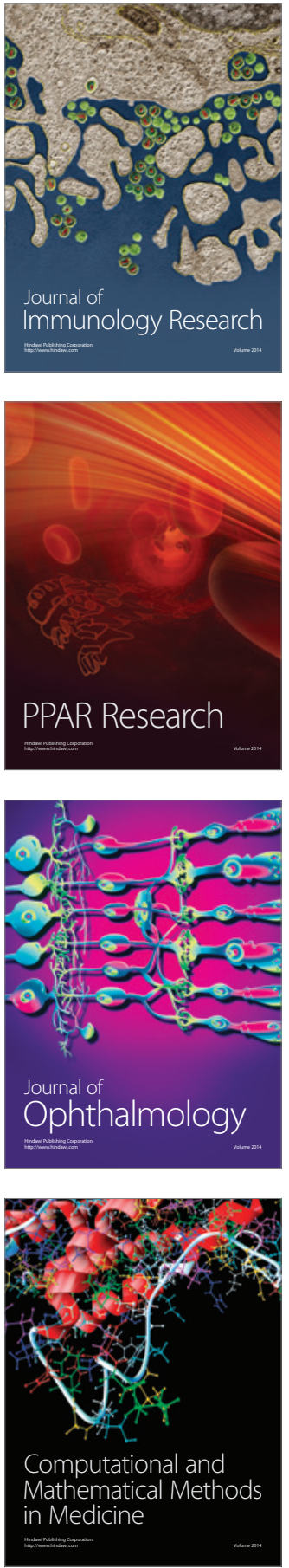

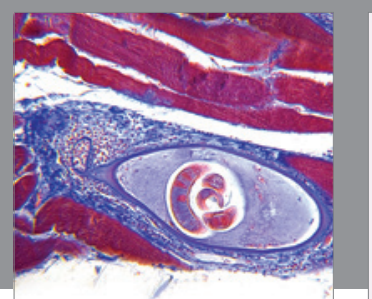

Gastroenterology Research and Practice

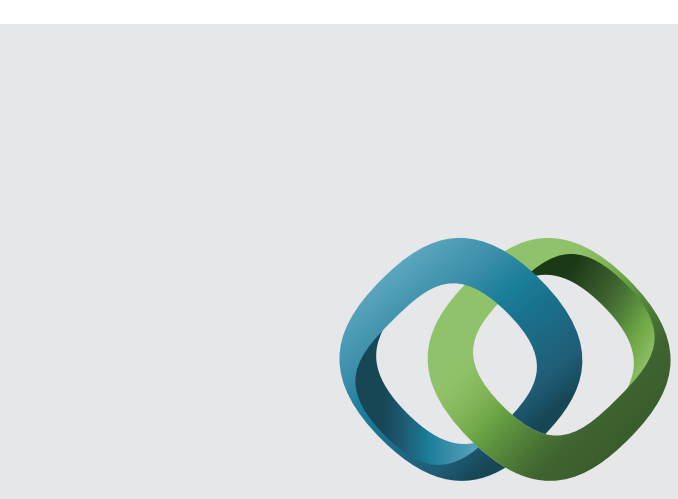

\section{Hindawi}

Submit your manuscripts at

http://www.hindawi.com
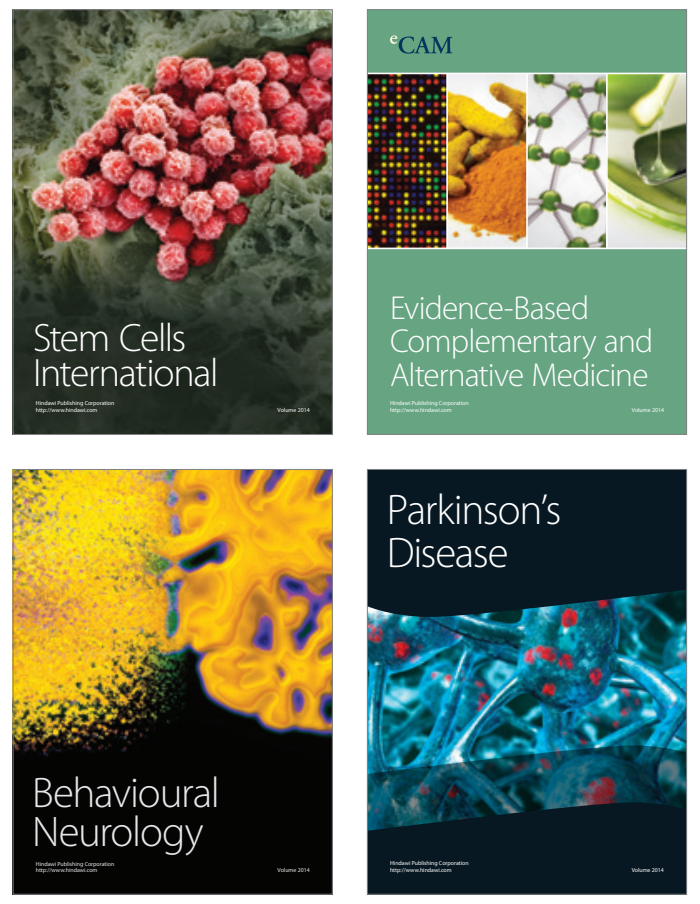
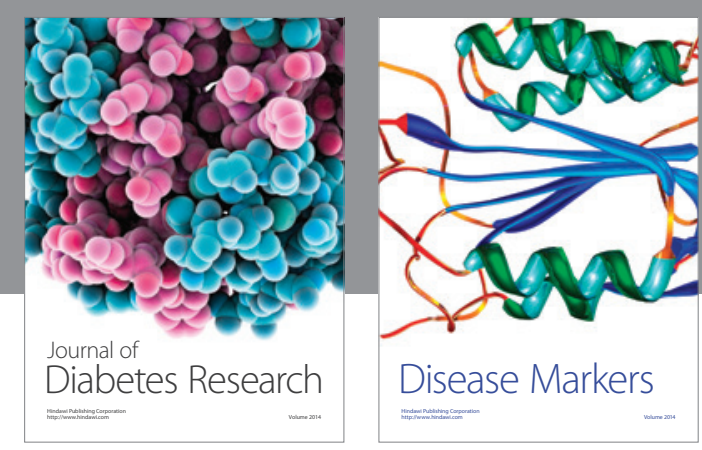

Disease Markers
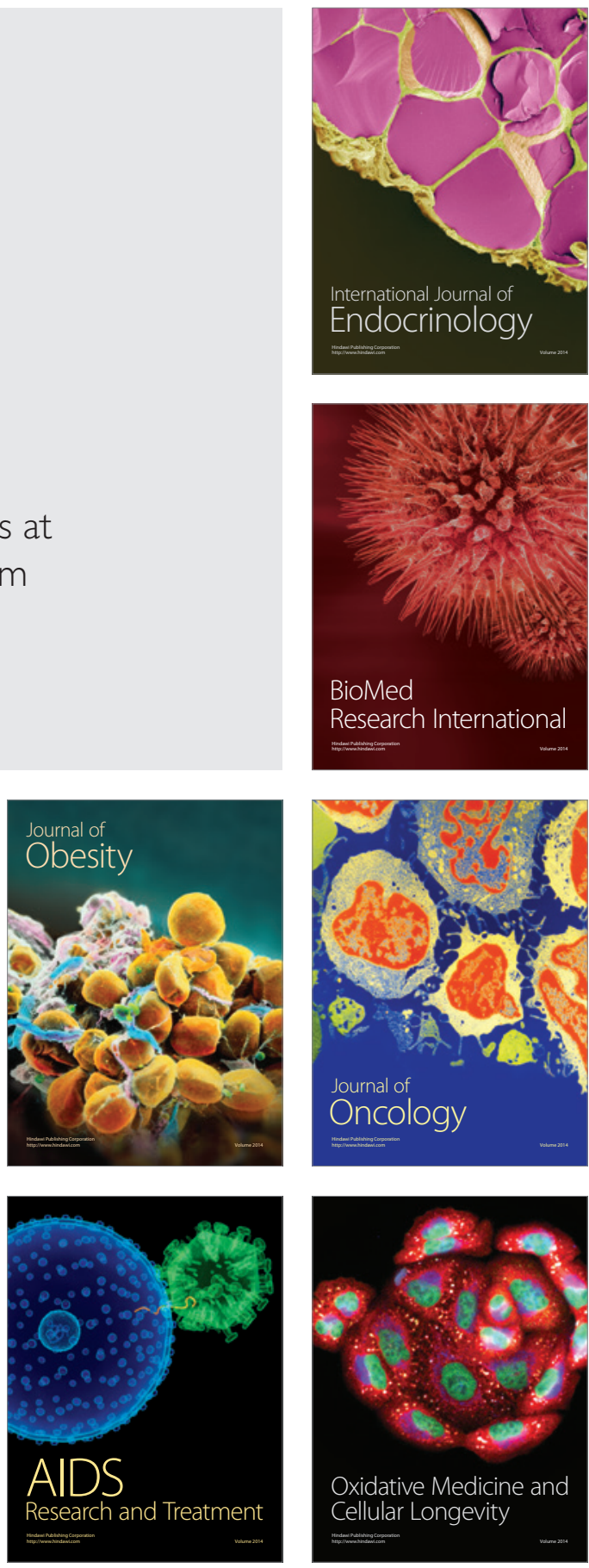